\title{
Bureaucratic Hierarchy vs. Feudal Hierarchy: A Study on the Organizational Culture of China's SOEs
}

\author{
Tianyuan Yu \\ Institute of Enterprise Management, School of Business, Sun Yat-Sen University \\ International Business Faculty, Beijing Normal University, Zhuhai Campus \\ Jin Feng Road, Tangjiawan, Zhuhai 519087, China \\ Tel: 86-756-612-6600Ｅ-mail: tianyuanyu@gmail.com
}

Nengquan $\mathrm{Wu}$

Institute of Enterprise Management, School of Business, Sun Yat-Sen University

135Xin Gang Xi Road, Guangzhou 510275, China

Tel: 86-20-8411-4155 E-mail: wnq@vip.163.com

\begin{abstract}
Bureaucratic Hierarchy and Feudal Hierarchy are two confusing concepts in organization literature, especially in the study of the organizational culture of enterprises in China. This article clarifies the two concepts in the first place. Ralston et al. (2006) and Tsui et al. (2006) suggested that the dominant organizational culture of China's state-owned enterprises (SOEs) was Bureaucratic Hierarchy, consistent with Quinn and Cameron (1983)'s "life cycles - criteria of effectiveness model". However, according to Boisot and Child (1996)'s "Chinese and Western paths to modernization" model, China's SOEs are dominated by Feudal Hierarchy culture. This article proposes that the dominant organizational culture of SOEs remains to be Feudal Hierarchy, and then critically examines the literature to support this proposition. Finally, it points to key obstacles in the codification/modernization process of China.
\end{abstract}

Keywords: Bureaucratic hierarchy, Feudal hierarchy, Organizational culture

\section{Bureaucratic Hierarchy vs. Feudal Hierarchy}

Ralston et al. (2006)'s and Tsui et al. (2006)'s studies are two pioneering and influential empirical research on the organizational culture of enterprises in the Chinese context. Both research come to the conclusion that the dominant organizational culture of China's state-owned enterprises (SOEs) is Bureaucratic Hierarchy. Based on critical literature review, however, this article suggests that the dominant organizational culture of China's SOEs is not Bureaucratic Hierarchy, but "mock bureaucracy" (Boisot and Child, 1996, p.605), or Feudal Hierarchy indeed. Thus it is necessary to distinguish between Bureaucratic Hierarchy and Feudal Hierarchy in the first place.Bureaucratic Hierarchy is one of the four organizational culture types contained in the Competing Values Framework (CVF, Quinn and Rohrbaugh, 1983, Figure 1). CVF is one of the most influential and extensively used models in the area of organizational culture research. Using two comprehensive value dimensions (internal vs. external, control vs. flexibility), CVF classifies four organizational culture types: Clan, Hierarchy, Market, and Adhocracy, among which Hiearchy is referred to as Bureaucratic Hierarchy in this article. Quinn and Cameron (1983) suggested that there were close relationships between stages of development in organizational life cycles and the four culture types in the CVF. Their "life cycles-criteria of effectiveness model" hypothesized that major organizational culture types would change in predictable ways as organizations developed through life cycles. In the entrepreneurial stage, the strongest culture type appears to be Adhocracy. In the collectivity stage, organizations are characterized by the Clan culture. In the formalization stage, culture types are primarily Bureaucratic Hierarchy and Market (Quinn and Cameron, 1983, p.42-44; Yu and Wu, 2009).

Bureaucratic Hierarchy is the typical organizational culture of mature enterprises in western countries. Examples range from American fast food chain stores to large corporations (e.g., Ford) and government agencies, etc. (Cameron and Quinn, 1999). The notion of Bureaucratic Hierarchy can be traced to Weber's early works on general administrative theories. Weber (1964) described an ideal Bureaucracy as characterized by division of labor, clearly defined hierarchy, detailed rules and regulations, formal selection, career orientation, and 
impersonal relationships (i.e., impersonality). These characteristics are very effective in large, standardized organizations that emphasize a clear organizational structure, standardized rules and procedures, strict control, and well defined responsibilities.

The concept of Feudal Hierarchy is attributed to "Culture-space model" ("C-space model", Boisot, 1986, Figure 2). Boisot (1986, p.138) considered the notion of culture as a system of shared meanings or knowledge. He described culture in two paths: how meanings are constructed and how meanings are shared. Accordingly the "C-space model" has two dimensions: The vertical axis indicates the process of knowledge creation, labeled codification, defined as the selection and compression of data into stable structures (Boisot and Child, 1996, p.602). The horizontal axis is labeled diffusion, the extent to which transactionally relevant information can be diffused and shared within a target population. The two dimensions create four national culture types at the macro level: Bureaucracy, Market, Clan, and Fief, which correspond to four organizational culture types in turn: Bureaucratic Hierarchy, Market, Clan, and Feudal Hierarchy.

According to "C-space model", both Bureaucratic Hierarchy and Feudal Hierarchy are featured by undiffused information, which implies centralized authority. Centralization generates hierarchical structure hence both types of culture are termed hierarchy. Their difference lies in the degree of information codification. Specifically, the former has a codified knowledge system whereas the latter has an uncodified one. Therefore, Bureaucratic Hierarchy is run by impersonal, formal rules and regulations, and Feudal Hierarchy is maintained by the leaders' personal power and influences. Boisot (1986, p.145) highlighted that the term "hierarchy" covers two distinct processes that must not be confused: personal and impersonal transactions. In particular, this article considers the level of impersonality (or the extent of codification) as the key difference between Bureaucratic Hierarchy and Feudal Hierarchy.

The key feature of Bureaucratic Hierarchy is a high level of codification. The authors suggest that codification brings benefits to organizations in at least three aspects.

Firstly, codification decreases transaction cost incurred by employee turnover. High rates of turnover dilute the Clan culture and cause loss of organization knowledge. Ouchi (1979) argued that through extensive training programs and monitoring regulations, Bureaucratic Hierarchy could withstand high rates of turnover and a high degree of heterogeneity prevailing in modern society.

Secondly, codification reduces transaction cost caused by expansion of transaction scale. Boisot and Child (1996, p.603) contended that the depersonalization associated with codified transactions in western countries merely reflected the difficulty of maintaining a dense network of interpersonal obligations as small- numbers transacting gave way to large-numbers transacting.

Thirdly, knowledge management and impersonal transactions promotes organization development and nation modernization. Codification and workflow management contribute to organizational learning by the process of converting tacit knowledge into explicit knowledge. North (1973) was concerned that the rise of the western world could be seen as a history of the increment and diffusion of knowledge. He argued that modern economic growth led to complex contracts, and impersonal transactions based on market rules were the key foundation of modernization. According to this view, codification not only promotes organizational learning, but also advances a nation's modernization progress.

\section{A Proposition on the organizational culture of China's SOEs}

The proposition in this article on the organizational culture of China's SOEs supports the "Chinese and Western paths to modernization model" (Boisot and Child, 1996, Figure 2) which is established on the basis of "C-space model". This model suggests that China is trending a path toward modernization that differs from Western experience.

Boisot and Child (1996) argued that in the sixteenth and seventeenth centuries emergent nation states in Europe created strong centralizing bureaucracies that codified a rational-legal approach to government administration. Only with the advent of a liberal ideology in the eighteenth and nineteenth centuries did decentralization to a market order gradually take place. Accordingly, the Western path to modernization, involving first a shift from Feudal Hierarchy toward Bureaucratic Hierarchy and, second, from there a decentralization toward a market order, created the institutions of modern "market capitalism". By contrast, China had not actually built up a stable codified bureaucratic order in the history. The Chinese economic reform since 1978 was a process of delegation or decentralization. Under the economic reform, the only tools available to central policy makers for bringing the economy under control remained the direct administrative authorities of local governments. The implementation of laws was thus manipulated by personalized local authorities to a large extent. Therefore, the 
Chinese path to modernization since 1978 involved decentralization in the lower reaches of the C-space. Such decentralization led not to markets but to clans and permitted the more local and personalized institutional order, which were labeled by Boisot and Child (1996, p.622) "network capitalism". In the context of network capitalism, enterprises handle uncertainty by personalized guanxi. In other words, the security of property rights, which, according to the Western tradition was guaranteed by the rule of law in democratic societies, in China derived primarily from guanxi with local authorities. In this way, China experienced rapid economic growth at a low level of codification.

This article holds that in the context of network capitalism, dominant organizational culture tends to be Feudal Hierarchy as national culture appears to be Clan. China's SOEs have a typical culture of Feudal Hierarchy, and lack the change force towards Bureaucratic Hierarchy. Due to agency problems, formal rules and regulations are not strictly implemented in China's SOEs. Rather, opportunism prevails in organizations. Moreover, the formal rules and regulations of China's SOEs are far less comprehensive than those of mature enterprises in the West. The bonding mechanisms in SOEs are not rules and regulations, but leaders' personal charisma and influences. In other words, in western countries with small power distance, rigid hierarchy is maintained by one's compliance with formal rules. In China's SOEs with large power distance, rigid hierarchy originates from one's "official oriented consciousness". Therefore, the organization culture of SOEs is "mock bureaucracy" or Feudal Hierarchy indeed.

Based upon the arguments above, this article presents the following proposition: The dominant organizational culture of China's SOEs remains to be Feudal Hierarchy.

\section{A literature review on the organizational culture of SOEs}

Ralston et al. (2006)'s and Tsui et al. (2006)'s empirical research display certain evidence in support of the article's proposition. Moreover, Zhang and Keh (2010)'s work provides theoretical grounds for the proposition. This section critically examines the three studies.

\subsection{A Review on Ralston et al. (2006) 's research}

Ralston et al. (2006)'s pioneering research studied the change of organizational culture within China's SOEs by comparing the SOEs to domestic private-owned enterprises (POEs) and foreign-controlled businesses (FCBs) in terms of their organizational cultures, using the CVF model and its matched scale, OCAI questionnaire. They proposed that pre-reform SOEs were dominated by the Bureaucratic Hierarchy and Clan cultures; whereas today's SOEs had transformed to a configuration desired by the Chinese government, demonstrating Bureaucratic Hierarchy and Market cultures which was supposed to be globally competitive. That is to say, Bureaucratic Hierarchy remained to be a dominant culture of SOEs whenever before or after the economic reform was initiated. In addition, they assumed that the dominant cultures of POEs were Adhocracy and Clan; while for FCBs, Adhocracy and Market. Therefore, they hypothesized that on the Bureaucratic Hierarchy culture items in the OCAI, SOEs would score higher than both POEs and FCBs. Their sample consisted of 435 Chinese managers from 233 SOEs, 96 POEs and 106 FCBs. They conducted a multivariate analysis of covariance (MANCOVA) on the scores obtained in the questionnaire and resulted in four main findings. They declared that these findings strongly suggested that today's SOEs were embracing a Market culture in conjunction with the Bureaucratic Hierarchy orientation, which fit the "mature" stage in an organizational life cycle. The present article, by contrast, argues that Ralston et al. (2006)'s findings did not support their propositions after all. A critical discussion on each of the four relevant findings is as follows.

(1) The Market, Bureaucratic Hierarchy, and Clan cultures were not significantly different from one another within SOEs, while all three were scored significantly higher than the Adhocracy culture. This result certainly did not support the dominance of Bureaucratic Hierarchy in the SOEs, only evidencing the weakness of Adhocracy.

(2) The SOEs were not significantly different from the FCBs on the Bureaucratic Hierarchy culture items. This finding obviously did not support Ralston et al. (2006)'s hypothesis that SOEs would score higher than FCBs on these items. Actually, the present article holds that the SOEs in China should be far weaker on Bureaucratic Hierarchy than mature enterprises in the West. A possible reason of Ralston et al. (2006)'s finding that there was no significant difference between the two might be a fact evidenced by the third finding: Bureaucratic Hierarchy is no longer a dominant culture of FCBs operating in China, due to certain constraints of the Chinese context.

(3) In the FCBs, there were no significant differences across the four organizational cultures. Apparently this finding failed to support Ralston et al. (2006)'s hypothesis that FCBs were dominated by the Adhocracy and Market cultures. Neither did it support this article's view that FCBs should have a strong Bureaucratic Hierarchy 
culture. It might be due to the fact that part of the sample of FCBs in their study were actually sino-foreign joint ventures which were founded on the basis of pre-existing SOEs or collectives (Ralston et al., 2006, p.827). In addition, it is possible that, to cope with demands by the Chinese context, FCBs may have adjusted their organization culture originated from their home countries. Such adjustments tend to increase organization flexibility, hence Adhocracy and Clan cultures strengthened, while Bureaucratic Hierarchy weakened.

(4) The SOEs scored significantly higher than the POEs on the Bureaucratic Hierarchy culture items. This result seems in conflict with this article's proposition. A possible reason for this result could be that, Bureaucratic Hierarchy is more prevalent among large enterprises than in small ones, and SOEs are usually much larger than POEs. However, this finding could not prove the dominance of Bureaucratic Hierarchy in SOEs, either. Because the reliability for Bureaucratic Hierarchy items in the OCAI scale did not meet the accepted standards. Ralston et al. (2006, p.837) tested the scale reliability using the Cronbach alpha coefficient. The reliabilities for each culture type were: $\mathrm{Clan}=0.84$, Adhocracy $=0.80$, Market $=0.67$, and Bureaucratic Hierarchy $=0.50$. Generally, a value above 0.6 is considered adequate to conclude internal consistency. Thus they admitted that the results for the Bureaucratic Hierarchy items might be questioned. The present article suggests that this problem may be due to certain flaws in the validity and reliability of the CVF and OCAI in the context of China.

To be specific, the CVF does not incorporate the notion of Feudal Hierarchy, a type of culture widespread among indigenous Chinese enterprises because of the long tradition of feudal hierarchy in China's history. This problem may undermine the validity and reliability of the CVF and OCAI in their applications in China. In some case studies conducted in China by the authors, certain contradictions between questionnaire data and interview data have been spotted repeatedly. Through further communication with the responders, the authors found discrepancies between the description of Bureaucratic Hierarchy in the OCAI and its connotation in the CVF. That is, the reliability of the OCAI is questionable. Specifically, the Bureaucratic Hierarchy culture items in the OCAI merely emphasize rules and regulations, without any mention of work procedures or knowledge management. Furthermore, those descriptions of Bureaucratic Hierarchy imply strict hierarchy and centralized authority, coinciding with Feudal Hierarchy while neglecting the difference between the two. One can speculate that SOEs certainly have strict hierarchy and centralized authority, and a formalized system apparently, similar with Bureaucratic Hierarchy. Thus a responder in the SOEs would probably allocate a high score to the Bureaucratic Hierarchy items in the OCAI.

As suggested above, Ralston et al. (2006)'s empirical study failed to support their propositions on the organizational culture of China's SOEs. In particular, because of the validity problem of the CVF and OCAI highlighted in this article, their findings for the Bureaucratic Hierarchy items are suspicious. Indeed, their empirical findings evidenced that SOEs might be dominated by Feudal Hierarchy.

\subsection{A Review on Tsui et al. (2006)'s research}

Tsui et al. (2006)'s research aimed to develop and validate a measure of organizational culture in the Chinese context. Their work reported three studies. In the first study, 79 managers from POEs and 63 managers from FCBs were asked to describe the organizational culture of their companies by responding to an open-ended questionnaire. Afterwards, the investigators coded and categorized the respondents' statements to extract both common dimensions and unique dimensions for the two types of firms. It turned out that Standardization was a unique dimension to FCBs, with a relatively high frequency of mention by respondents from FCBs, ranking the second among all seven dimensions. By contrast, standardization was rarely mentioned by respondents from POEs. They then compared the results with those by Xin et al. (2002)'s study on the organizational culture of SOEs and found that standardization was not included in the value dimensions list of SOE managers, neither. In the authors' view, this finding implies that, compared with their counterparts of FCBs, managers of SOEs and POEs lack the notion of standardization such as work procedures and rules and regulations, demonstrating weakness on the Bureaucratic Hierarchy culture.

The second study aimed to identify the organizational culture profile for each of the three types of firms. Tsui et al. (2006, p.354-355) argued that SOEs in a planned economy were less concerned with customers than meeting production quotas or adhering to the commands by the government. Moreover, because of the restructuring and "privatization" in many SOEs along with massive layoffs, employee development is limited and harmony disrupted. Therefore, they hypothesized that the organizational culture of SOEs would have a low emphasis on both the internal integration and external adaptation values, relative to the other two types of firms. They designed a questionnaire containing five common culture dimensions (employee development, harmony, customer orientation, outcome orientation, innovation), and surveyed 542 managers. Using a cluster analysis, a four-cluster typology was generated, which, in their view, showed similarity with the CVF. In particular, a cluster 
with low scores on all culture values was considered similar to Bureaucratic Hierarchy, for they thought that the emphasis on formal rules, policies and procedures by the Bureaucratic Hierarchy culture implied low scores on cultural/informal values (Tsui et al., 2006, p.359). Then they conducted a $\chi^{2}$-test and, consistent with their hypothesis, more of the SOEs showed a Bureaucratic Hierarchy culture than the FCBs and POEs (Tsui et al., 2006, p.360). Their third study mainly attempted to re-test their hypotheses and validate their measure of organizational culture. They concluded that an emphasis on any cultural values would be better than no emphasis at all as represented by Bureaucratic Hierarchy (Tsui et al., 2006, p.371).

The present article holds that Bureaucratic Hierarchy in the CVF corresponds to a high score on the dimension of standardization, with the focus on formal rules and procedures. However, due to its uniqueness exhibited by only FCBs managers, standardization dimension was not incorporated in the questionnaire designed by Tsui et al. (2006). Hence the questionnaire was incapable of measuring the responders' attitudes toward standardization. The finding that SOEs scored low on all five culture dimensions is certainly not equivalent to a high score on the standardization dimension. On the contrary, as discussed previously, their first study has already shown that SOEs managers were not concerned with standardization issues at all. Therefore, it is most likely that the dominant organizational culture of SOEs is not Bureaucratic Hierarchy, but Feudal Hierarchy.

Accordingly, Tsui et al. (2006)'s empirical research also provided evidence in support of the proposition of the present article.

\subsection{A Review on Zhang and Keh (2010)'s research}

Zhang and Keh (2010) examined the governance mechanisms of SOEs, POEs and FCBs in China. Based on institutional theory, they identified two basic forms of governance: contractual governance and guanxi governance. It has been noted that organizational culture is closely related to governance mechanisms (Hofstede et al., 1990). In specific, Bureaucratic Hierarchy corresponds to contractual governance which relies on formal rules and procedures, and Feudal Hierarchy corresponds to guanxi governance which counts on informal processes.

Zhang and Keh (2010) analyzed the characteristics of SOEs based on the resource dependence theory, agency theory, and evolutionary theory. They made the proposition that SOEs used both guanxi and contracts with the former playing a more important role, because of the following three lines of arguments:

(1) According to resource dependence theory (Pfeffer and Salancik, 1978/2003), organizations with important and scarce resources have power advantage over others in negotiations. Zhang and Keh (2010, p.103) argued that SOEs enjoyed resource and policy advantages (bank loans, industry policy protection, etc.), often leading to advantageous bargaining positions. These resource advantages, combined with their ownership and serious agency problems, created many problems such as waste and misuse of resources, endemic corruption, and the stripping of state assets. These problems hindered contractual governance in effect.

(2) As stated by agency theory (Fama and Jensen, 1983), agency problems create opportunities for individuals within an organization to benefit themselves at the cost of the organization. Organizations with agency problems are likely to become victims of opportunism. For instance, SOE managers can benefit themselves by choosing their acquaintances as transaction partners or selecting business partners who offer them gifts. Zhang and Keh (2010, p.130) pointed out that currently the State Asset Commission at various levels of government served as agents of the state to oversee SOEs, but these agents often lacked the appropriate incentive, skill, and information to monitor SOEs well. At the same time, supervision and monitoring from the government superiors and the legal environment remained largely deficient.

(3) Based on evolutionary theory (Nelson and Winter, 1982), organization histories, structures and traditions can shape organizational choices of governance mode. Zhang and Keh $(2010$, p.131) revealed that though SOEs had developed a bureaucratic tradition of formal structures and procedures in their operating routines, these formal structures and procedures did not serve as effective internal governance mechanisms, but rather acted more as rituals. Evidence suggested that, even for corporatized firms, boards of directors and supervisory boards existed in form rather than in substance (Dahya et al., 2003; Mar and Young, 2001). Zhang and Keh (2010, p.131) made the following observation:

"Therefore, we see the duplicity of SOEs. On the surface, they have formal structures and bureaucratic procedures. When dealing with them, one has to go through various departments and personnel, obtaining numerous seals/signatures and performing a lot of paperwork, which has the appearance of contractual governance and does indeed lead to some use of contracts as a governance mechanism. However, beneath the surface, acute agency problems in SOEs allow parties both within and external to an SOE to resort to personal 
contacts/ties or bribes to advance their interests as well as to benefit their collaborators, which reflect the use of guanxi. As such, it is likely that SOE managers may behave opportunistically, colluding privately with other parties to pursue personal wealth."

The present article suggests that Zhang and Keh (2010)'s research provides theoretical support for the proposition that SOEs are dominated by Feudal Hierarchy culture. And their three lines of arguments can also be considered as reasons for the stagnation of Feudal Hierarchy culture in SOEs: firstly, SOEs possess policy advantage and monopoly positions and thus lack market competition pressures; secondly, serious agency problems and deficient supervision undermine SOEs' drive for improving efficiency; finally, the relatively long organization histories may bring higher culture inertia to SOEs compared with POEs in China.

\section{Obstacles in China's codification process}

In respect of the stagnation of Feudal Hierarchy culture in SOEs, this article considers it associated with the resistance force in the codification process of Chinese society. In the authors' view, China faces two significant obstacles on the path of codification/modernization in comparison with the West: the shortage of both intellectual and political support.

Firstly, China's codification process is in shortage of intellectual support. In this regard, besides the bounded rationality of human beings, China is also limited by the absence of "formal rationality" (Weber, 1964) in contrast with the West. Child $(2009$, p.59) contended that the core of formal rationality in the West was "calculable terms" (Weber, 1964, p.185; Huang, 1997). On the other hand, China's governance mode in the traditional society was termed "substantive rationality" (Weber, 1964, p.185-186; Child, 2009, p.60), which concerned people's spirituality and values. China's traditional bureaucratic systems are noted as filled with numerous rites and rituals, with the focus on Confucian orthodoxy and formal perfection rather than actual conditions or effects (e.g. Boisot and Child, 1996, p.604; Child, 2009, p.60; Huang, 1997, p.14). The authors suggest that, the reason that traditional Chinese bureaucrats put so much address on those rites and rituals is because they never attempt to utilize "calculable terms", but count on Confucian orthodoxy to govern the people. In other words, while western societies are concerned more with material issues, namely "formal rationality", China focuses on spiritual issues and hence is known as "substantive rationality". This cultural tradition leads to the weakness of government administration capacity of modern China. To date China has not yet grasped the "calculable terms" at a comparable level with western developed countries. At the organization level, most enterprises still lack experts on scientific management or codification processes. In this respect, indigenous enterprises could learn little from each other, and have to borrow from the West and start from scratch.

Secondly, China's codification process is in lack of political support. Due to the low level of codification in the Chinese society, opportunism prevails within the ruling class. Because of the traditional desire by Chinese leaders to maintain their personal authority, rulers have been prepared, when necessary, to counter moves toward a rational-legal bureaucracy that might limit their discretion and to maintain a patrimonial style of governance (Boisot, 1988, p.513). Boisot and Child (1996:604) highlighted that the absence of a rational-legal institutional framework failed to engender confidence in a wider system of bureaucratic or market transacting outside networks based on personal power, commitment, and trust. In a highly personalized social order, vested interest groups would seek to develop and strengthen their social network continuously. Therefore, the process is self-reinforcing. Boisot and Child (1996) labeled this tendency the "iron law of fiefs". The present article considers the "iron law of fiefs" an explanation of the "middle-income trap" of China. In other words, it is the struggle by vested interest groups to protect and promote their interests that hinders China from breaking through the "network Capitalism".

\section{Conclusion}

This article has made the proposition that SOEs in China are dominated by Feudal Hierarchy culture, and lack the change force towards Bureaucratic Hierarchy. It is argued that Ralston et al. (2006)'s and Tsui et al. (2006)'s studies offer empirical evidence, and Zhang and Keh (2010)'s work provides theoretical support for this proposition. This proposition is in line with Boisot and Child (1996)'s "Chinese and Western paths to modernization model", with the implication that the powerful existence of SOEs in China directs the nation towards an order of "network Capitalism".

\section{References}

Boisot, Max \& John Child. (1988). The Iron Law of Fiefs: Bureaucratic Failure and the Problem of Governance in the Chinese Economic Reforms. Administrative Science Quarterly, 33, 507-27.

Boisot, Max \& John Child. (1996). From Fiefs to Clans and Network Capitalism: Explaining China's Emerging 
Economic Order. Administrative Science Quarterly, 41(4), 600-28.

Boisot, Max. (1986). Markets and Hierarchies in a Cultural Perspective. Organization Studies, 7(2), 135-58.

Cameron, Kim S., \& Robert E. Quinn. (1999). Diagnosing and Changing Organizational Culture: Based on the Competing Values Framework. Reading, MA: Addison-Wesley Longman.

Child, John. (2009). Context, Comparison, and Methodology in Chinese Management Research. Management and Organization Review, 5(1), 57-73.

Dahya, J., Y. Karbhari, J. Xiao, \& M. Yang. (2003). The Usefulness of the Supervisory Board Report in China. Corporate Governance, 11(4), 308-21.

Fama, E., \& M. Jensen. (1983). Agency Problems and Residual Claims. Journal of Law and Economics, 25(2), $327-49$.

Hofstede, G., B. Neuijen, et al. (1990). Measuring Organizational Cultures: A Qualitative and Quantitative Study across Twenty Cases. Administrative Science Quarterly, 35(2), 286-316.

Huang, Ray. (1997). China - A Macro History. Beijing: SDX Joint Publishing Company.

Mar, P., \& M. N. Young. (2001). Corporate Governance in Transition Economies: A Case Study of Two Chinese Airlines. Journal of World Business, 36(3), 280-302.

Nelson, R., \& S. Winter. (1982). An Evolutionary Theory of Economic Change. Cambridge, MA: Harvard University Press.

North, Douglass C., \& Robert Paul Thomas. (1973). The Rise of the Western World. Cambridge: Cambridge University Press.

Ouchi, William G. (1979). A Conceptual Framework for the Design of Organizational Control Mechanisms. Management Science, 25(9), 833-48.

Pfeffer, J., \& G. Salancik. (1978/2003). The External Control of Organizations. (2nd ed.) Stanford, CA: Stanford University Press,

Quinn, Robert E., \& John Rohrbaugh. (1983). A Spatial Model of Effectiveness Criteria: Towards a Competing Values Approach to Organizational Analysis. Management Science, 29(3), 363-77.

Ralston, David A., Jane Terpstra-Tong, Robert H. Terpstra, Xueli Wang, \& Carolyn Egri. (2006). Today's State-Owned Enterprises Of China: Are They Dying Dinosaurs Or Dynamic Dynamos? Strategic Management Journal, 27(9), 825-43.

Tsui, Anne S., Hui Wang, \& Katherine R. Xin. (2006). Organizational Culture in China: An Analysis of Culture Dimensions and Culture Types. Management and Organization Review, 2(3), 345-76.

Weber, Max. (1964). The Theory of Social and Economic Organization. New York: Free Press.

Xin, Katherine R., Anne S. Tsui, Hui Wang, Z. Zhang, \& W Chen. (2002). Corporate Culture in Chinese State-owned Enterprises: An Inductive Analysis of Dimensions and Influences [A]. In Tsui, Anne S. \& C. M. Lau. (Eds.), The Management of Enterprises in the People's Republic of China. Boston, MA: Kluwer Academic Press.

Yu, Tianyuan \& Nengquan Wu. (2009). A Review of Study on the Competing Values Framework. International Journal of Business and Management, 7, 37-42.

Zhang, Jianjun \& Hean Tat Keh. (2010). Interorganizational Exchanges in China: Organizational Forms and Governance Mechanisms. Management and Organization Review, 6(1), 123-47. 


\section{Flexibility}

$\underline{\text { Human Relations Model (Clan) }}$

Means: Cohesion; morale

Ends: Human resource development

\section{Open System Model (Adhocracy)}

Means: Flexibility; readiness

Ends: Growth; resource acquisition

\section{Internal}

Means: Information management; communication

Ends: Stability; control

$\underline{\text { Internal Process Model (Hierarchy) }}$

\section{External}

Means: Planning; goal setting

Ends: Productivity; efficiency

$\underline{\text { Rational Goal Model (Market) }}$

Control

Figure 1. Competing Values Framework (CVF)

(Quinn and Rohrbaugh, 1983, p.369)

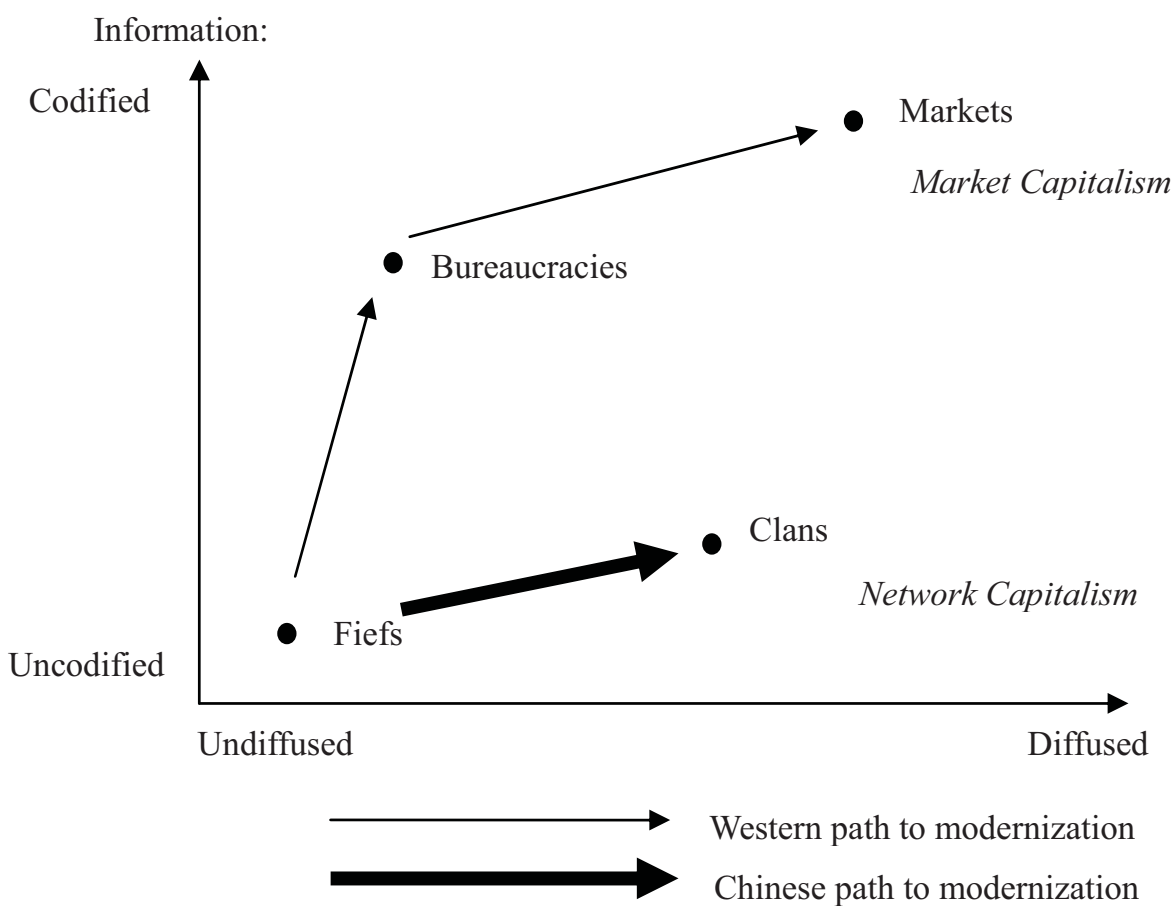

Figure 2. Chinese and Western paths to modernization (Based on C-space model)

(Boisot and Child, 1996, p.622) 